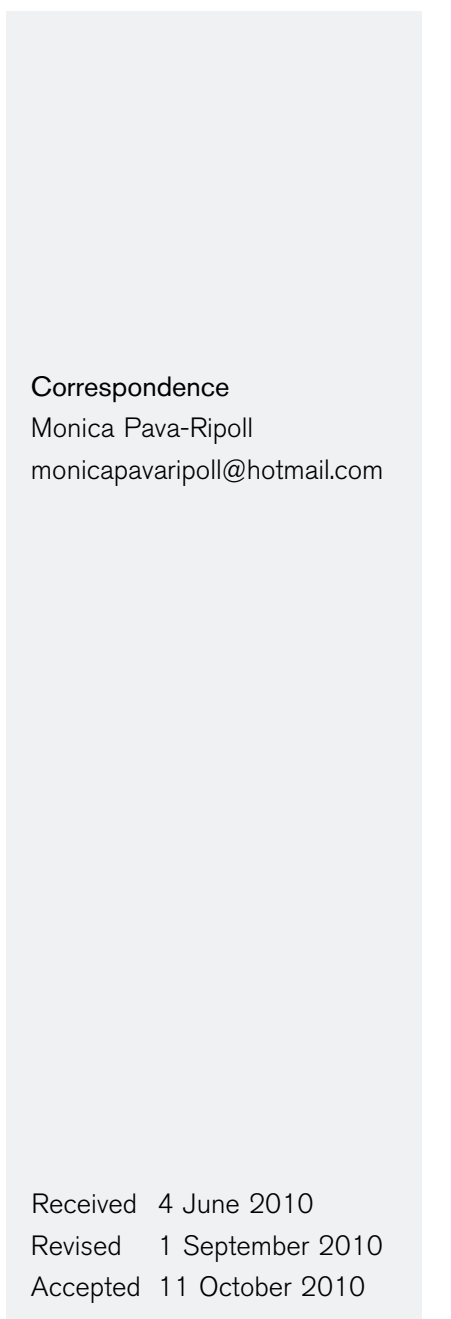

\title{
The rhizosphere-competent entomopathogen Metarhizium anisopliae expresses a specific subset of genes in plant root exudate
}

\author{
Monica Pava-Ripoll, ${ }^{1}$ Claudia Angelini, ${ }^{2}$ Weiguo Fang, ${ }^{1}$ Sibao Wang, ${ }^{1}$ \\ Francisco J. Posada ${ }^{1}$ and Raymond St Leger ${ }^{1}$ \\ ${ }^{1}$ Department of Entomology, University of Maryland, College Park, MD 20742, USA \\ ${ }^{2}$ Istituto per le Applicazioni del Calcolo, 'Mauro Picone', CNR-Napoli, Italy
}

\begin{abstract}
Metarhizium anisopliae and Beauveria bassiana are ubiquitous insect pathogens and possible plant symbionts, as some strains are endophytic or colonize the rhizosphere. We evaluated 11 strains of M. anisopliae and B. bassiana, and two soil saprophytes (the non-rhizospheric Aspergillus niger and the rhizosphere-competent Trichoderma harzianum) for their ability to germinate in bean root exudates (REs). Our results showed that some generalist strains of $M$. anisopliae were as good at germinating in RE as $T$. harzianum, although germination rates of the specialized acridid pathogen Metarhizium acridum and the $B$. bassiana strains were significantly lower. At RE concentrations of $<1 \mathrm{mg} \mathrm{ml}^{-1}$, M. anisopliae strain ARSEF 2575 showed higher germination rates than T. harzianum. Microarrays showed that strain 2575 upregulated 29 genes over a $12 \mathrm{~h}$ period in RE. A similar number of genes (21) were downregulated. Upregulated genes were involved in carbohydrate metabolism, lipid metabolism, cofactors and vitamins, energy metabolism, proteolysis, extracellular matrix/cell wall proteins, transport proteins, DNA synthesis, the sexual cycle and stress response. However, $41.3 \%$ of the upregulated genes were hypothetical or orphan sequences, indicating that many previously uncharacterized genes have functions related to saprophytic survival. Genes upregulated in response to RE included the subtilisin $\operatorname{Pr} 1 \mathrm{~A}$, which is also involved in pathogenicity to insects. However, the upregulated Mad2 adhesin specifically mediates adhesion to plant surfaces, demonstrating that $M$. anisopliae has genes for rhizosphere competence that are induced by RE.
\end{abstract}

\section{INTRODUCTION}

The entomopathogen Metarhizium anisopliae is a soil fungus with worldwide distribution (Zimmermann, 2007). Some strains of $M$. anisopliae are rhizosphere-competent (Hu \& St. Leger, 2002; St. Leger, 2008), which may explain the persistence of $M$. anisopliae in soils for long periods of time in the absence of an insect host (Bidochka et al., 2001). In grasslands, populations of M. anisopliae can reach up to $10^{6}$ propagules $\mathrm{g}^{-1}$ at $2-6 \mathrm{~cm}$ deep (Milner, 1992).

M. anisopliae is presumably subject to different selective pressures during insect colonization and soil survivability (Prior, 1992; St. Leger, 2008; Wang et al., 2005), but

Abbreviations: EST, expressed sequence tag; LEM, linear expression map; RE, root exudate.

The microarray data discussed in this paper are available from the NCBI Gene Expression Omnibus (GEO) database under accession number GSE16848.

Two supplementary tables, showing a list of taxa used in this study and the $\log _{2}$ expression ratios of 50 differentially expressed $M$. anisopliae genes, are available with the online version of this paper. overall, the genetic groups of $M$. anisopliae and their geographical distribution seem shaped by their adaptability to specific soils and habitat types rather than for their pathogenicity to insects (Bidochka et al., 1998; QuesadaMoraga et al., 2007). It is likely that the distribution of different genotypes of $M$. anisopliae will depend upon environmental factors, such as temperature and humidity, and soil conditions, such as $\mathrm{pH}$ and organic matter content (Quesada-Moraga et al., 2007; Zimmermann, 2007). In addition insects, plants and microbial populations will interact at the soil-root interface to affect Metarhizium populations (St. Leger, 2008). Similarly, complex interactions occur with the best-known rhizosphere-competent fungus Trichoderma harzianum. This fungus is also used as a biocontrol agent because it can parasitize plant fungal pathogens and establishes a symbiotic relationship with the roots of some plants, increasing plant growth and productivity (Harman, 2006). Complex interactions between multiple strains of Trichoderma, the roots of plants and other fungal pathogens suggest an established molecular cross-talk between them (Woo et al., 2006). However, the genetic and physiological factors controlling 
rhizosphere competence in fungi, including Trichoderma, are little understood (St. Leger, 2007). In fact, for many economically important pathogens, the least studied aspect of their biology involves the extended periods for which they survive in soil in the absence of a suitable host (Kerry, 2000). Thus, while a lot of research has been performed on the entomopathogenicity of $M$. anisopliae, its saprophytic lifestyle has received little consideration. Presumably, the same functionally related genes could be adaptive for multiple different environments [insect cuticle, insect blood and root exudates (REs)], but there might also exist different subsets of genes that are adaptive to each environment (Wang et al., 2005).

In this study, we performed a time-course evaluation of gene expression by M. anisopliae growing on plant REs as the first step in elucidating pathways that are used by this fungus for soil survivability and adaptability. We need this knowledge to be able to predict and control outbreaks of plant or animal disease. In addition, lack of knowledge of the fate of fungal genotypes at the population and ecosystem levels creates an inherent uncertainty about the efficacy, survivability and environmental risk posed by any introduced or engineered fungi. A deeper understanding of the mechanistic basis of rhizosphere competency could enable us to identify genes that we could use to develop $M$. anisopliae as a comprehensive plant symbiont, or at least improve persistence and consequently provide greater long-term protection against insect pests.

\section{METHODS}

Bean REs. In order to simulate rhizospheric conditions in the laboratory, M. anisopliae was grown on bean REs from black pea seeds (Vigna unguiculata subsp. unguiculata). To obtain the RE, bean seeds were disinfected by soaking them for $2 \mathrm{~min}$ in $95 \%$ ethanol, rinsed in sterile distilled water and transferred to $30 \%$ hydrogen peroxide (Fisher Scientific) for $1 \mathrm{~min}$. The disinfected seeds were rinsed three times in sterile distilled water and placed on wet, sterile paper for initial germination. Seedlings were then transferred to containers with sterile distillated water and kept there connected to an aquarium air pump until roots were formed (about 1 week). The water in which the plants were growing was collected in $50 \mathrm{ml}$ sterile tubes and freeze-dried. The dried RE was dissolved in sterile water to produce a stock solution of $40 \mathrm{mg} \mathrm{ml}^{-1}$, and filter-sterilized before storage at $-20{ }^{\circ} \mathrm{C}$.

Fungal strains and spore germination in REs. We evaluated 11 entomopathogens from the genera Beauveria and Metarhizium, and two soil saprophytes, Aspergillus niger ATCC 10574 (non-rhizospheric) and $T$. harzianum strain T22, a model rhizospherecompetent strain (Harman, 2006), at five concentrations of bean $\operatorname{RE}\left(1,2.5,5,10\right.$ and $\left.20 \mathrm{mg} \mathrm{ml} \mathrm{m}^{-1}\right)$. Information about the geographical area and insect host (if entomopathogenic) of each fungal strain is shown in Supplementary Table S1.

Each fungal strain was grown on Sabouraud dextrose agar (SDA) (Fisher Scientific) for 2 weeks at $27{ }^{\circ} \mathrm{C}$. A final concentration of $10^{4}$ spores $\mathrm{ml}^{-1}$ in $0.01 \%$ Tween 20 was prepared, and $100 \mu \mathrm{l}$ was added to sterile tubes containing $900 \mu \mathrm{l}$ of the selected concentration of RE. Fungal spores were also added to $0.1 \%$ yeast extract (Fisher Scientific) and sterile distilled water as positive and negative controls, respectively. Three replicates were performed for each treatment combination (fungal strains and RE concentrations).

The percentage spore germination of each fungus was determined after $24 \mathrm{~h}$ incubation at $27{ }^{\circ} \mathrm{C}$ with shaking (250 r.p.m.). In order to detect differences between T. harzianum and M. anisopliae, we also evaluated their germination at concentrations lower than $1 \mathrm{mg} \mathrm{ml}^{-1}$ $\left(0.01,0.05,0.1\right.$ and $\left.0.5 \mathrm{mg} \mathrm{ml}^{-1}\right)$.

Data were analysed using one-way analysis of variance (ANOVA) (SAS Institute Inc, 2006). A $P$ value $<0.05$ determined the significance level.

Culture conditions and total RNA extraction. For microarray analyses, M. anisopliae mycelium inocula from Sabouraud dextrose broth (SDB) cultures (Wang et al., 2005) were suspended in $20 \mathrm{ml}$ sterile distilled water. Five millilitres of the mycelial suspension was transferred to four $50 \mathrm{ml}$ flasks, each containing sufficient RE to give a final concentration of $5 \mathrm{mg} \mathrm{RE} \mathrm{ml}^{-1}$. This relatively high concentration was not limiting to growth during the course of the experiment, thus avoiding changes in gene expression due to nutritional deprivation alone. Samples were incubated at $27{ }^{\circ} \mathrm{C}$ at 220 r.p.m., and mycelium was collected from individual flasks after 1, 4, 8 and $12 \mathrm{~h}$ of incubation. Total RNA was immediately extracted from the samples using the Qiagen RNeasy Mini kit according to the manufacturer's instructions, and treated with Qiagen DNase I. Two biological replicates were performed.

cDNA microarray. For microarray analysis, we used cDNAs isolated from three libraries that were previously constructed using mycelia of M. anisopliae (ARSEF 2575), grown on insect cuticle (Freimoser et al., 2003), or grown in insect blood or plant REs (Wang et al., 2005). PCR-amplified expressed sequence tags (ESTs) were spotted on $\gamma$-aminopropyl II-coated glass slides (Corning, Inc.), following the standard protocol developed at the University of Maryland Biotechnology Institute (http://www.umbi.umd.edu/carb/core-facilities/ microarray-services/facility.php). A total set of 1748 unigenes (870 from cuticle, 276 from haemolymph and 602 from the root library) were printed in triplicate per slide. Blanks using water and saline sodium citrate (SSC) buffer were also included as negative controls. The genes were classified in nine groups of functionally related genes, and this classification was also used to initiate comparisons of expressed genes (Wang et al., 2005).

Microarray design and RNA hybridization. To analyse expression profiles in RE, we applied a loop design protocol, where every time point was compared with the previous time point. The contrast between adjacent time points provides information about the expression pattern of a gene over time. Total RNA from fungal mycelia grown in SDB (time 0$)$ and RE at each time point (1, 4, 8 and $12 \mathrm{~h}$ ) was amplified and directly labelled with Cy3 (green) and Cy5 (red) cyanine dyes using the Ovation Aminoallyl system (Nugen). Five slides were hybridized per replicate (time 0 vs 1 h, 1 h vs 4 h, 4 h vs $8 \mathrm{~h}, 8 \mathrm{~h}$ vs $12 \mathrm{~h}$ and $12 \mathrm{~h}$ vs time 0 ). Competitive hybridization of the second biological replicate was performed using a reverse dyeassignment to eliminate bias from dye incorporation.

Microarray data analysis. Hybridized slides were scanned at the University of Maryland Biotechnology Institute (http://www.umbi. umd.edu/carb/core-facilities/microarray-services/facility.php) using an Axon 4200 microarray scanner (Molecular Devices). To obtain differential signal expression, the TIFF images generated (two image files per hybridized slide) were analysed using the Spotfinder program (http://www.tm4.org/spotfinder.html). Data were then normalized using the LOWESS (LOcally WEighted Scatterplot Smoothing) technique with MIDAS software (http://www.tm4.org/midas.html). MIDAS output files included standard deviation regularization, lowintensity filters and in-slide replicate analysis. 
To detect differentially expressed genes in our time-course microarray experiment, the $\log _{2}$ expression ratios $(\mathrm{Cy} 5 / \mathrm{Cy} 3$ for replicate 1 and Cy3/Cy5 for replicate 2) were calculated per gene at each time point in the two replicates. Normalized data were inputted to the Bayesian Analysis of Time Series Microarray Experiments (BATS) software (version 1.0) (http://www.na.iac.cnr.it/bats/) (Angelini et al., 2008). To account for the time instants we chose as parameter of the analysis the maximum expected degree of polynomial equal to 3 , the parameter lambda for the truncated Poisson prior probability equal to 4 (corresponding to an expected polynomial degree of about 2), and we accounted for multiple comparisons using the Bayesian Multiple Testing Procedure with the binomial prior. Default values were used for the other parameters.

Validation of differentially expressed genes by RT-PCR. Total RNA extracted for microarray analysis was also used for RT-PCR using the VersocDNA kit (Thermo Fisher Scientific) and oligo-dT primers according to the manufacturer's protocol. The cDNA product was subsequently amplified by PCR using gene-specific primers. As a control, RT-PCRs were also performed using the constitutively expressed glyceraldehyde-3-phosphate dehydrogenase ( $g p d a)$ gene.

\section{RESULTS}

\section{Fungal strains and spore germination on bean REs}

All fungal strains showed some germination in RE at $1 \mathrm{mg}$ $\mathrm{ml}^{-1}$. T. harzianum and the broad-host-range M. anisopliae strain 2105 showed the highest germination rates at the five concentrations of RE (ranging from 1 to $20 \mathrm{mg}$ $\mathrm{ml}^{-1}$ ) (Fig. 1a). These germination rates ranged from 96.8 to $99.3 \%$, and did not differ significantly from each other. M. anisopliae strains 2575,549 and 1080 with a broad host range had germination rates ranging from 76.6 to $93.9 \%$ at $1 \mathrm{mg} \mathrm{ml}{ }^{-1}$ of $\mathrm{RE}$, germination rates ranging from 91.6 to $95.2 \%$ at $2.5 \mathrm{mg} \mathrm{RE} \mathrm{ml} \mathrm{ml}^{-1}$, and germination rates ranging from 87 to $93 \%$ at $5 \mathrm{mg} \mathrm{ml}^{-1}$. These germination rates were not significantly different from those of the model rhizospheric fungus $T$. harzianum at the same concentrations of RE. However, strain 2575 showed a significantly lower germination rate as compared with $T$. harzianum at concentrations greater than $5 \mathrm{mg} \mathrm{RE} \mathrm{ml}{ }^{-1}$ (Fig. 1a).

The specialist M. acridum strain 324, specific to locusts and related grasshoppers (Orthoptera: Acrididae), is not rhizosphere-competent (O'Brien, 2008). We also tested other strains of Metarhizium with unknown host ranges, including M. anisopliae strains 4600 and 4620 , which were isolated from the Tasmanian soldier fly (Diptera: Stratiomyidae), and M. anisopliae strain 2974, recently reclassified in the Agriculture Research Service Entomopathogenic Fungal Collection (ARSEF) collection as Metarhizium brunneum, originally isolated from a mosquito (Diptera: Culicidae) (Supplementary Table S1). These strains have very low rhizosphere competence as determined by microcosm studies (O'Brien, 2008). M. acridum 324 showed its highest germination rate $(47.3 \%)$ at $1 \mathrm{mg} \mathrm{RE} \mathrm{ml} \mathrm{m}^{-1}$ and its lowest germination rate $(24.7 \%)$ at $20 \mathrm{mg} \mathrm{RE} \mathrm{ml}^{-1}$. Germination rates of $M$. acridum 324 were significantly different from those of both $T$. harzianium and $A$. niger at each concentration of RE (Fig. 1a). The lowest germination frequencies with $1 \mathrm{mg} \mathrm{RE} \mathrm{ml}{ }^{-1}$ were shown by $M$. anisopliae strains $4620(22.5 \%), 2974(12.5 \%)$ and 4600 (6.5\%), and A. niger (19.3\%). However, germination rates of the M. anisopliae strains increased at higher concentrations of RE (except at $20 \mathrm{mg} \mathrm{ml}^{-1}$, when strains 4620 and 2974 showed slightly reduced germination rates), while the germination rate of A. niger declined with increasing concentrations of $\mathrm{RE}$ (germination rates of $A$. niger were 19.3, 14, 13, 2 and $0 \%$ at concentrations of $1,2.5,5,10$ and $20 \mathrm{mg} \mathrm{RE} \mathrm{ml}{ }^{-1}$, respectively) (Fig. 1a).

B. bassiana strains 9205 and 9112 were isolated from Lepidopteran hosts (Supplementary Table S1). B. bassiana strain 3113 was isolated from soil but is an endophyte able to colonize corn plants and provide protection against lepidopteran pests (Pingel \& Lewis, 1996; Wagner \& Lewis, 2000). At $1 \mathrm{mg} \mathrm{RE} \mathrm{ml}^{-1}$, germination rates of B. bassiana strains 9205, 9112 and 3113 were 73, 50.5 and $64 \%$, respectively. These germination rates were not significantly different from each other, but they were significantly higher than those of A. niger and Metarhizium strains 4620, 2974 and 4600 (Fig. 1a). Germination rates of B. bassiana strains 9112 and 3113 were significantly lower than those of the M. anisopliae generalist strains $(2105,2575,549$ and 1080) and T. harzianum strain T22. B. bassiana strains 9112 and 9205 showed slightly increased germination at 2.5 and

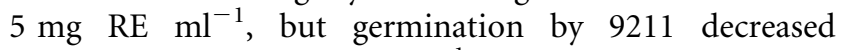
significantly at $20 \mathrm{mg} \mathrm{RE} \mathrm{ml}{ }^{-1}$. Germination rates of $B$. bassiana strain 3113 gradually declined at concentrations $>1 \mathrm{mg} \mathrm{ml}^{-1}$ and had diverged significantly from the other fungal strains at $10 \mathrm{mg} \mathrm{RE} \mathrm{ml}^{-1}$ (Fig. 1a).

In order to detect any differences between $T$. harzianum and M. anisopliae strains 2105 and 2575 we evaluated concentrations of RE lower than $1 \mathrm{mg} \mathrm{ml}^{-1}$. Fig. 1(b) shows that at concentrations $\leqslant 0.5 \mathrm{mg} \mathrm{ml}^{-1}$ the germination rate of $T$. harzianum was significantly lower than that of $M$. anisopliae 2575. The percentage germination of strain 2105 was $1,12.5$ and $42 \%$ with $0.01,0.05$ and $0.1 \mathrm{mg} \mathrm{RE}$ $\mathrm{ml}^{-1}$, respectively, whereas germination rates of strain 2575 were 88.6, 98 and $93 \%$ at the same concentrations. This indicates that strain 2575 of $M$. anisopliae is hypersensitive to RE.

\section{Microarray data analysis}

Out of 1748 genes included in the cDNA microarrays, we identified 50 genes $(2.9 \%)$ that were differentially expressed across the time points evaluated. Differentially expressed genes were automatically detected using BATS and ranked according to their Bayes factors $(\mathrm{BF}<0.006)$. Nucleotide query sequences of these genes were subsequently compared against the already existing sequences in the NCBI non-redundant protein database (BLASTX) (http://blast.ncbi.nlm.nih.gov/) and reorganized into previously classified groups of functionally related genes (Wang et al., 2005) (Fig. 2a). M. anisopliae genes that 
(a)

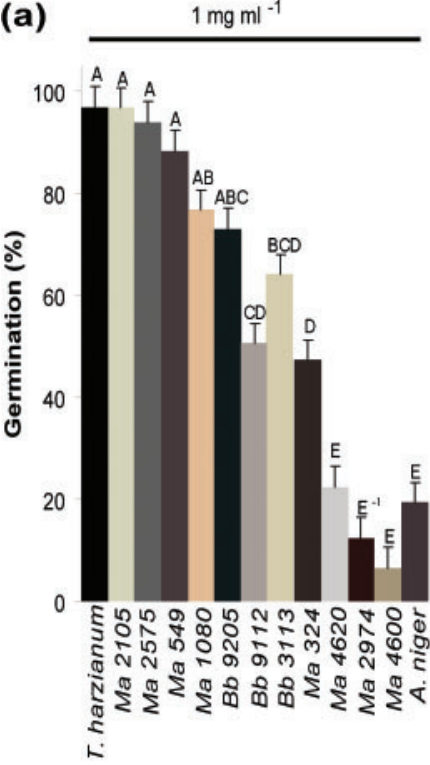

$2.5 \mathrm{mg} \mathrm{m}^{-1}$

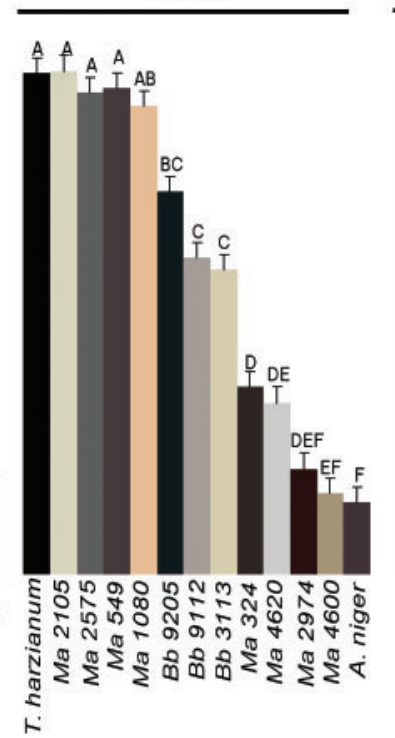

$5 \mathrm{mg} \mathrm{m}^{-1}$

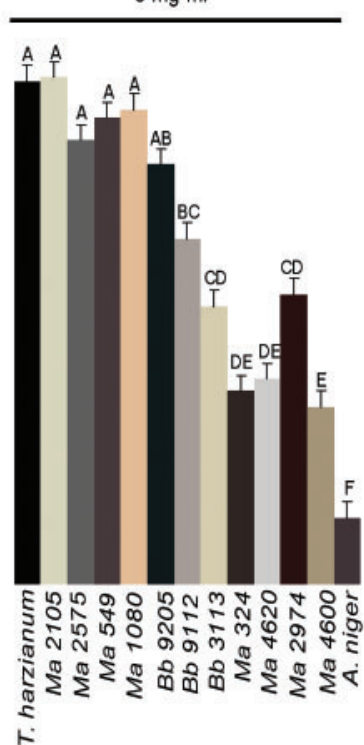

$10 \mathrm{mg} \mathrm{ml}^{-1}$

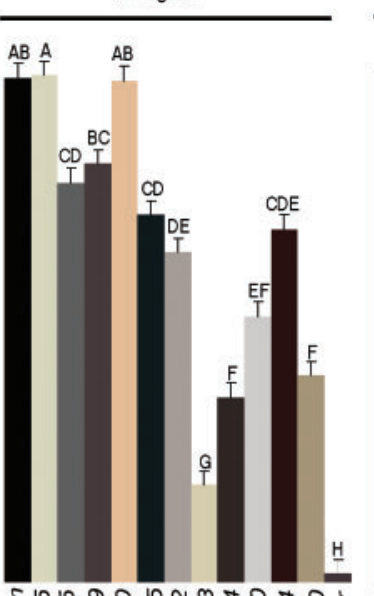

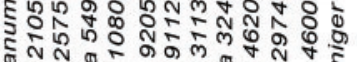

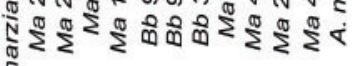

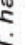

$20 \mathrm{mg} \mathrm{ml}^{-1}$

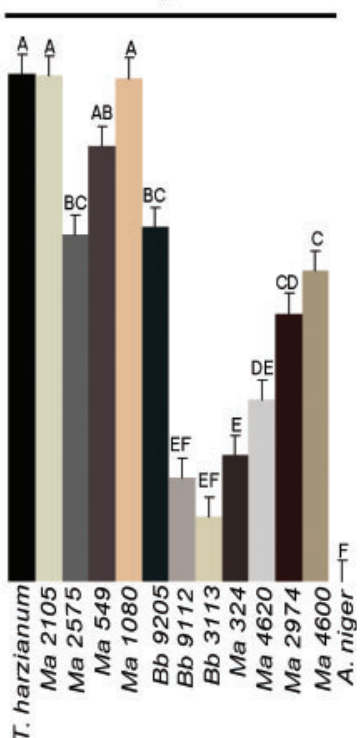

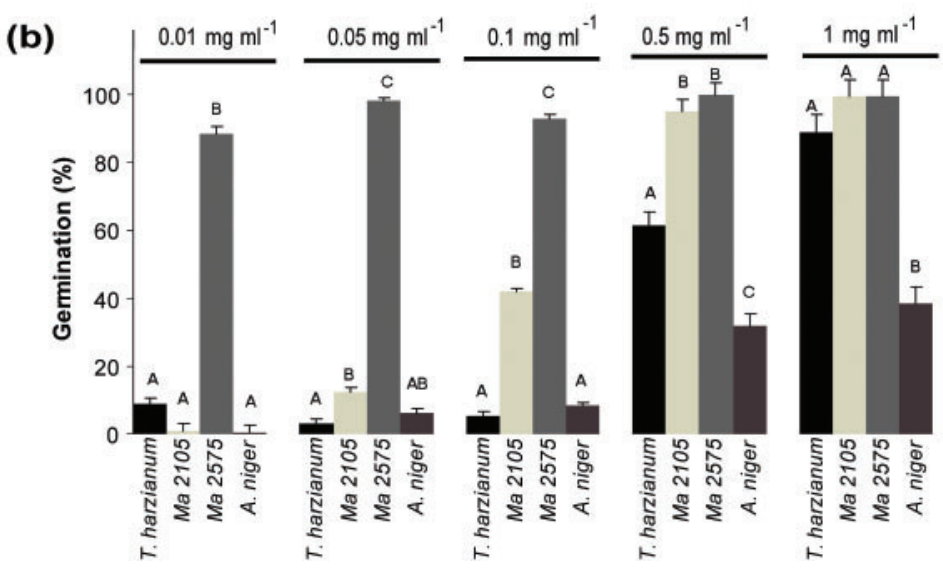

Fig. 1. Germination of Metarhizium (Ma) strains, $B$. bassiana (Bb) strains, $T$. harzianum (rhizospheric) and $A$. niger at different concentrations of REs. (a) Concentrations of RE from 1 to $20 \mathrm{mg} \mathrm{ml}^{-1}$. (b) Concentrations of $\mathrm{RE}<1 \mathrm{mg} \mathrm{ml}^{-1}$. Mean values labelled with the same letter are not significantly different $(P<0.05)$. 


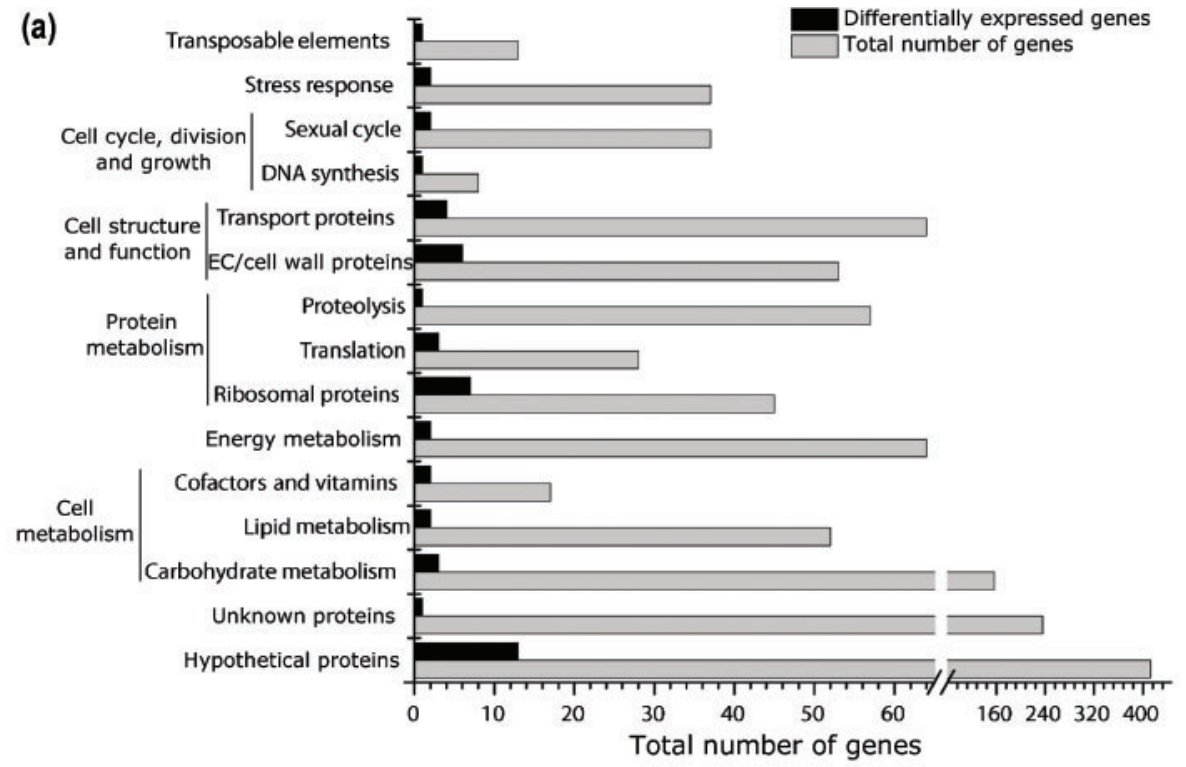

(b)

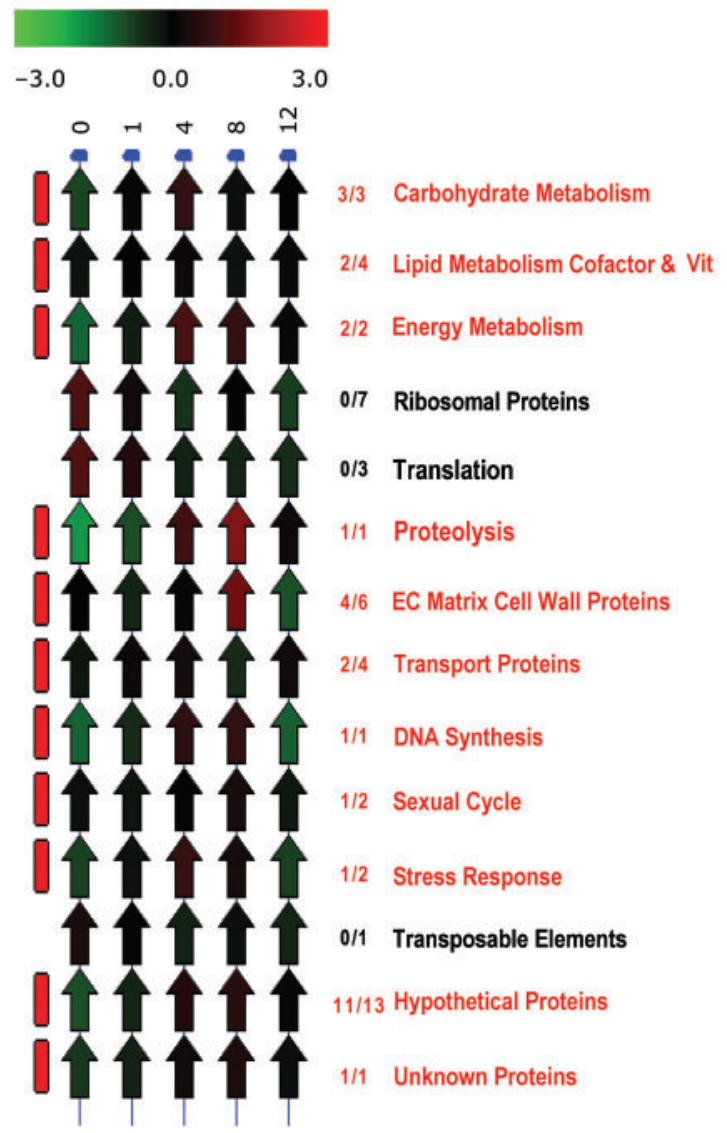

(c)

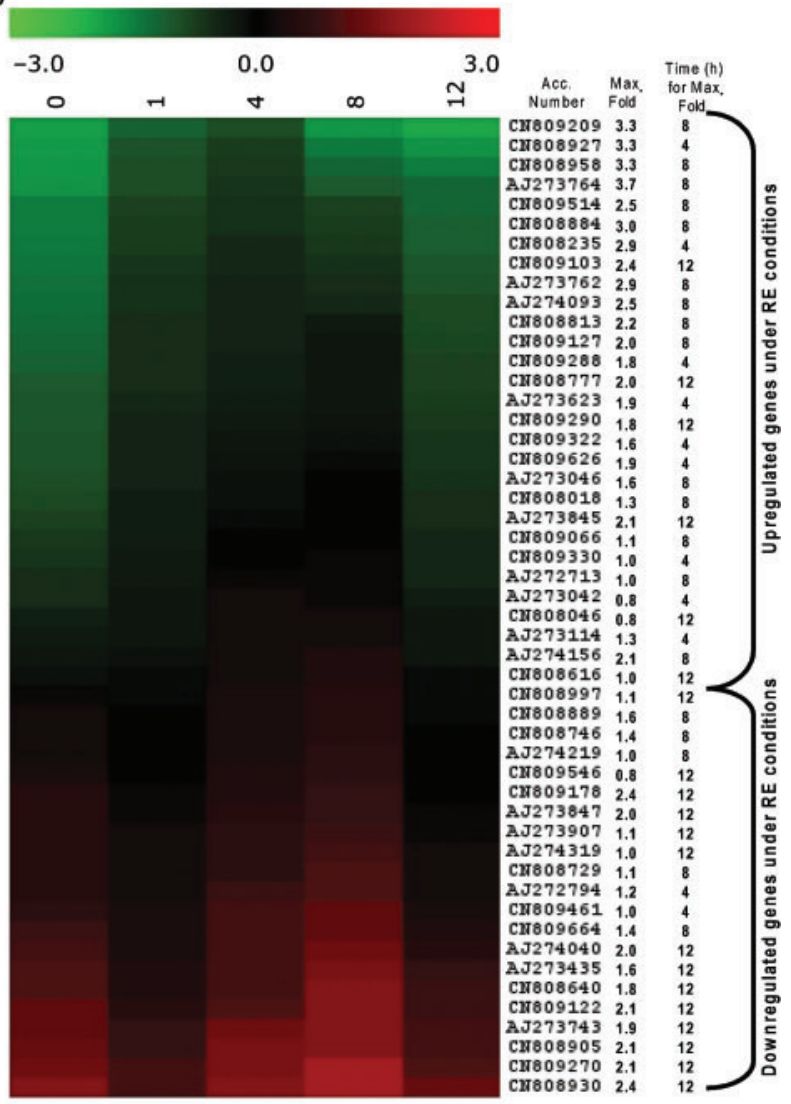

Fig. 2. Fifty genes differentially expressed by $M$. anisopliae 2575 during growth in RE. (a) Differentially expressed genes compared with the total number of genes in each functional group. (b) LEM representing the mean of the differentially expressed genes organized according to functional groups. The vertical red bars show functional groups that contain genes that were upregulated at one or more points. The number of upregulated genes/total number of differentially expressed genes per functional group is also shown. (c) Pattern of expression of the differentially expressed genes after $0,1,4,8$ and 12 h growth in RE. GenBank accession numbers, the maximum fold values (Max. fold) and the time (h) when the maximum fold value occurred are provided. 
were differentially expressed under RE conditions over $12 \mathrm{~h}$ included 13 out of 413 arrayed hypotheticals (predicted sequences with homologues in other organisms but no experimental evidence of function) (13/413, 3.1\%), an orphan sequence with no homologues in databases $(1 / 236,0.4 \%)$ and genes involved in cell metabolism $(7 / 335,2.1 \%)$, energy metabolism $(2 / 64,3.1 \%)$, protein metabolism $(11 / 172,6.4 \%)$, cell structure and function $(10 / 231,4.3 \%)$, cell cycle, division and growth (3/93, $3.2 \%)$, transposable elements $(1 / 13,7.7 \%)$, and stress response and defence (2/107, $1.9 \%$ ) (Fig. 2a).

Overall, 27 (54\%) of these genes were originally isolated from the EST root library, 18 (36\%) from the cuticle library and five $(10 \%)$ from the insect blood library of M. anisopliae 2575. Thus, many genes expressed during cuticle degradation and growth in insect blood are also involved in adaptation to RE.

Fig. 2(b) shows the linear expression map (LEM) with the mean of the $\log _{2}$ ratio of differentially expressed genes classified by functional groups at each time point. Of the 50 differentially expressed genes, 29 (58\%) were upregulated across all time points when the fungus was transferred from SDB (time 0) to RE. They were involved in carbohydrate metabolism $(3 / 29,10.4 \%)$, lipid metabolism, cofactors and vitamins $(2 / 29,6.9 \%)$, energy metabolism $(2 / 29, \quad 6.9 \%)$, proteolysis $(1 / 29,3.4 \%)$, extracellular matrix/cell wall proteins $(4 / 29,13.9 \%)$, transport proteins $(2 / 29,6.9 \%)$, DNA synthesis $(1 / 29,3.4 \%)$, the sexual cycle $(1 / 29,3.4 \%)$, stress response $(1 / 29,3.4 \%)$, hypothetical proteins $(11 / 29,37.9 \%)$ and unknown proteins $(1 / 29$, $3.4 \%$ ) (Fig. 2b).

The level of expression of individual genes, the maximum fold change and the time (h) when the maximum fold change occurred are presented in Fig. 2(c). Of the 29 genes that were upregulated in RE, nine $(31 \%)$ obtained their maximum fold change after $4 \mathrm{~h}, 14(48 \%)$ after $8 \mathrm{~h}$ and six (21\%) after 12 h (Fig. 2c).

Supplementary Table S2 shows the $\log _{2}$ expression ratio through time of the 50 differentially expressed genes. The greatest fold increases were observed in the hypothetical genes. Gene AJ273764 was upregulated 3.7-fold (after 8 h), and genes CN808927 and CN809209 were both upregulated 3.3-fold after 4 and $8 \mathrm{~h}$, respectively. Genes CN808884, CN809514 and AJ274093 were upregulated $3.0-$, $2.5-$ and 2.5-fold, respectively, after $8 \mathrm{~h}$. The expression of the subtilisin-like serine protease $(\operatorname{Pr} 1 \mathrm{~A})$ gene (CN808958) increased through time in RE, being upregulated 3.3-fold after $8 \mathrm{~h}$. Genes involved in energy metabolism, dihydrolipoyl dehydrogenase (AJ273762) and oxidoreductase (CN808777), were upregulated 2.9- and 2.0 -fold after 8 and $12 \mathrm{~h}$, respectively. A stress response heat-shock protein gene (CN808235) was upregulated 2.9fold after $4 \mathrm{~h}$ in RE. Transport proteins, including an $\mathrm{ABC}$ transporter ATP-binding protein $(\mathrm{CN} 809103)$ and a GABA $(\gamma$-amino- $n$-butyrate) permease (CN808046) were upregulated 2.4 - and 0.8 -fold, respectively, after $12 \mathrm{~h}$. Genes required for the metabolism of carbohydrates such as glycosyl hydrolase (CN808813), $\beta$-glucosidase (AJ273623) and ferulic acid esterase A (faeA) (AJ273114) were also upregulated 2.2-fold (after $8 \mathrm{~h}$ ), 1.9-fold (after $4 \mathrm{~h}$ ) and 1.3-fold (after $4 \mathrm{~h}$ ), respectively. RE also increased the expression of genes encoding cell wall proteins and the associated extracellular matrix, including the hydrophobinlike protein precursor (AJ274156) and the predicted cell wall protein AJ273845, which were both upregulated 2.1fold at 8 and $12 \mathrm{~h}$. Also, the cell wall MAD2 adhesin (CN809626), which is required by M. anisopliae to adhere to plant surfaces (Wang \& St. Leger, 2007), and a close homologue (CN809322) were upregulated 1.9- and 1.6fold, respectively, after $4 \mathrm{~h}$. Other genes that are involved in the synthesis of DNA (mediator of replication checkpoint 1, CN809288), lipid metabolism (diacylglycerol O-acyltransferase, DgaT, CN808018), sexual development (EsdC protein, CN809127) and cofactors and vitamins (amidase protein, AJ273042) were also upregulated between 2.0- and 0.8 -fold after 4 and $8 \mathrm{~h}$ in RE. Although listed as a sex cycle gene, the gene for EsdC is involved in cell wall morphology and is expressed in asexual as well as sexual processes in Aspergillus (Han et al., 2008).

Twenty-one differentially expressed genes (42\%) were downregulated in RE (Fig. 2c, Supplementary Table S2). Two genes $(9.5 \%)$ were downregulated $\sim 1.2$-fold after $4 \mathrm{~h}$; 5 genes $(23.8 \%)$ were downregulated 1.0 to 1.6 -fold after $8 \mathrm{~h}$ and 14 genes $(66.7 \%)$ were downregulated 0.8 to 2.4 fold after $12 \mathrm{~h}$ (Fig. 2c). Downregulated genes included ribosomal proteins, the cold acclimation-induced protein 2-1 (CN808997), the carrier protein ADP/ATP translocase (CN809461) and hypothetical protein AJ272794. Expression of hydrophobin genes (AJ273847 and CN809178) was initially downregulated, but recovered so that by $8 \mathrm{~h}$ these genes were upregulated 1.5- and 1.6-fold, respectively. The C-3 sterol dehydrogenase protein AJ274219, the potassium channel protein CN808889 and the hypothetical protein CN808746 were upregulated during the first $4 \mathrm{~h}$ of incubation in RE before slowly declining, suggesting a role in the early stages of adaptation to RE.

\section{RT-PCR verification of differentially expressed genes}

Five genes (predicted protein AJ273764, subtilisin-like serine protease PR1A CN808958, hydrophobin-like protein AJ274156, Metarhizium adhesin protein Mad2 CN809626 and a ribosomal protein $\mathrm{CN} 809270$ ) were selected for validation of microarray analysis through RT-PCR. The results indicated that expression patterns of these genes were consistent with the microarray results (Fig. 3).

\section{DISCUSSION}

Root-mediated rhizosphere interactions are classified as being either positive or negative for the plant (Bais et al., 
2006). Mycorrhizal associations between fungi and plant roots are clearly positive, being essential for the survival of both partners. While the fungus obtains carbohydrates such as glucose and sucrose (final products of photosynthesis), the plant benefits from the increased uptake of water and nutrients, including nitrogen and phosphorus (Harman \& Shoresh, 2007). REs represent a significant carbon cost to the plant (Bais et al., 2006), but there is clearly coevolutionary potential in favouring populations of mycorrhizal fungi and also, presumably, populations of pathogens of herbivorous insects. It would not therefore be surprising if entomopathogenic fungi benefitted from components of REs when adapting to soil environments.

REs are composed of a complex mixture of soluble compounds such as carbohydrates, lipids, amino acids, organic acids, proteins, polysaccharides, nucleotides, flavonoids, growth factors, enzymes, growth inhibitors and repellants (Hale et al., 1978; Rovira, 1965). Our results show that generalist strains of M. anisopliae (ARSEF 2105, 2575,549 and 1080) are as good at germinating in RE as the model rhizosphere-competent fungus $T$. harzianum strain, 22. Specialist strains including strain 324 have lost genes compared with generalists, including genes for carbohydrate metabolism that may be required for a saprophytic existence on plant roots (Wang et al., 2009). Consistent with this, some strains of $M$. anisopliae with reduced rhizosphere competence need higher concentrations of REs to germinate (4620, 2974 and 4600). However, high concentrations of RE inhibit growth of $M$. acridum 324 and generalist strains $(2105,2575,549$ and 1080) to varying extents (Fig. 1a),

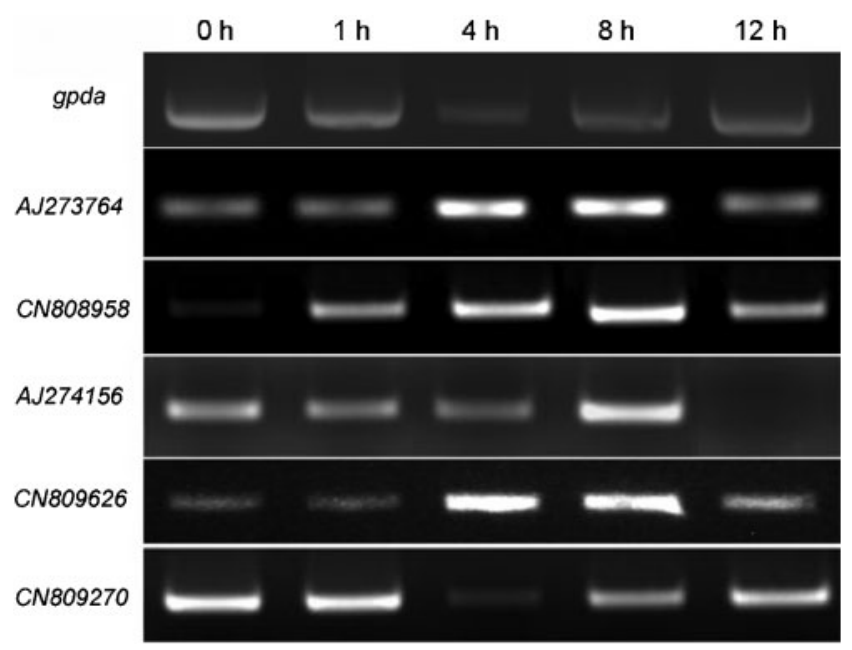

Fig. 3. RT-PCR to validate microarray gene expression of M. anisopliae 2575 growing in REs. Five differentially expressed genes were selected: predicted protein (AJ273764), subtilisin-like serine protease PR1A (CN808958), hydrophobin-like protein (AJ274156), Metarhizium adhesin protein Mad2 (CN809626) and a ribosomal protein (CN809270). The glyceraldehyde-3phosphate dehydrogenase ( $g p d a)$ gene was used as the reference gene. indicating that strains respond differently to the inductive and repressive components of RE. The non-rhizospheric fungus $A$. niger was the most sensitive to the inhibitors in $\mathrm{RE}$, indicating that is not adapted to resist antimicrobial exudate components. Fungi capable of rhizosphere competence presumably need to evolve resistance to these compounds, which are thought to have a role in defending the rhizosphere against pathogens (Bais et al., 2006).

M. anisopliae is found in most soils worldwide, and is able to survive for long periods of time in cultivated grassland soils without an insect host (Bidochka et al., 1998; Milner, 1992; Quesada-Moraga et al., 2007; St. Leger, 2008). Our results show that this fungus contains a set of differentially expressed genes that can rapidly adapt to nutrients present in RE. A previous study (Wang et al., 2005) showed that the overall pattern of gene expression in RE is mainly downregulated after $24 \mathrm{~h}$ at a low concentration of RE $\left(0.1 \mathrm{mg} \mathrm{ml}^{-1}\right)$. Here we demonstrated that the upregulation of genes under RE conditions occurs at earlier time points (mainly 4 and $8 \mathrm{~h}$ post-inoculation into RE), and that these upregulated genes have fold increases between 0.8 and 3.7 (Fig. 2c).

The category with the highest percentage of RE-induced upregulated genes $(41.4 \%)$ encodes hypothetical or unknown proteins, indicating that many previously uncharacterized Metarhizium genes may have functions related to saprophytic survival. Some of these genes have orthologues in plant pathogens and other soil fungi, so whatever role they play in adapting to soil conditions may be conserved. The presence of at least 10 sugars (including glucose, fructose, sucrose, raffinose, xylose, maltose and rhamnose, among others) has been identified in the RE of a wide variety of plants (Rovira, 1965). M. anisopliae genes involved in carbohydrate metabolism (glycosyl hydrolase CN808813, $\beta$-glucosidase AJ273623 and ferulic acid esterase AJ273114) were upregulated during the first $8 \mathrm{~h}$ under RE conditions. A formidable array of hydrolytic enzymes is secreted during the pathogenic life cycle of $M$. anisopliae, and these include the subtilisin protease Pr1A (CN808958) (Bagga et al., 2004; Wang et al., 2009). Pr1A was upregulated within $4 \mathrm{~h}$ of incubation in RE, and high-level expression was maintained throughout the timecourse, demonstrating an important long-term role in proteolysis for Pr1A in the utilization of RE. Cell wall proteins (e.g. adhesin proteins CN809626 and CN809322) were also upregulated in the first $4 \mathrm{~h}$. CN809626 encodes MAD2 (Metarhizium adhesin-like protein 2). Its detection in a screen of genes upregulated by RE helps validate the principle of using RE to identify genes involved in rhizosphere interactions. Strains of Metarhizium disrupted in Mad2 show a $90 \%$ reduction in adherence to plant cells (Wang \& St. Leger, 2007). In this study, we found an EST sequence in the root library CN809322, originally designated an unknown protein, but with $98 \%$ similarity ( $\mathrm{E}$ value 2e-136) to the MAD2 transcript (CN809626). Although expressed at lower levels than MAD2, it had an identical pattern of gene expression in RE (Supplementary Table S2). 
This suggests that CN809322 is also involved in attachment to plant surfaces, and it is perhaps responsible for the $10 \%$ of Mad2 mutant spores that are still adherent. An EST from the root library (CN809103) that was originally designated an unknown protein showed most $(46 \%)$ similarity to an $\mathrm{ABC}$ transporter (ATP-binding protein) from the symbiotic nitrogen-fixing actinobacterium Frankia alni (Supplementary Table S2). ABC transporter proteins are ubiquitous in all organisms and are primarily involved in the active transport of a wide array of different molecules across plasma membranes. Some ABC proteins serve as a cellular toxic defence mechanism by transporting deleterious compounds out of the cell. These may include xenobiotics, anthropogenic contaminants, natural product toxins and endogenous metabolites (Wolfger et al., 2001). A putative ABC transporter gene (CN809103) of M. anisopliae was upregulated after $1 \mathrm{~h}$ under RE conditions with a 2.4 -fold increase after $12 \mathrm{~h}$. This indicates that the protein may be required to facilitate the efflux of compounds present in RE that may be toxic to the fungus.

The rhizosphere competence of M. anisopliae and knowledge of the genes involved as it adapts and persists in soil environments is important when considering the potential commercial use of biological control agents against root herbivores and soil-borne plant pathogens. The long-term genetic adaptations and evolution of this fungus in cultivated soils (turf plots) are also being studied in our laboratory (O'Brien, 2008). Comprehensive knowledge of short- and long-term interactions between Metarhizium, insects, plants and microbial soil populations will reveal ecological links that will help us to understand the molecular cross-talk between them, and could ultimately be exploited to benefit plant growth and productivity. Further research is also needed to discern the function of the array of hypothetical/orphan proteins that were differentially expressed in RE in order to elucidate their roles in $M$. anisopliae, and possibly other fungi. The inability of mutants disrupted in MAD2 to adhere to plant roots provided a clear test of the importance to the fungus of root interactions, and confirms that the most informative approach for analysing the hypothetical proteins will involve comparisons with mutant fungi. Also, comparison of gene expression among rhizosphere-competent and non-rhizosphere-competent strains of Metarhizium would complement studies on the physiology of this fungus.

\section{ACKNOWLEDGEMENTS}

We thank Alvaro Godinez from the University of Maryland Biotechnology Institute for printing and performing competitive hybridization of microarray slides.

\section{REFERENCES}

Angelini, C., Cutillo, L., De Canditiis, D., Mutarelli, M. \& Pensky, M. (2008). BATS: a Bayesian user-friendly software for Analyzing Time Series microarray experiments. BMC Bioinformatics 9, 415.
Bagga, S., Hu, G., Screen, S. E. \& St Leger, R. J. (2004). Reconstructing the diversification of subtilisins in the pathogenic fungus Metarhizium anisopliae. Gene 324, 159-169.

Bais, H. P., Weir, T. L., Perry, L. G., Gilroy, S. \& Vivanco, J. M. (2006). The role of root exudates in rhizosphere interactions with plants and other organisms. Annu Rev Plant Biol 57, 233-266.

Bidochka, M. J., Kasperski, J. E. \& Wild, G. A. M. (1998). Occurrence of the entomopathogenic fungi Metarhizium anisopliae and Beauveria bassiana in soils from temperate and near-northern habitats. Can J Bot-Rev Can Bot 76, 1198-1204.

Bidochka, M. J., Kamp, A. M., Lavender, T. M., Dekoning, J. \& De Croos, J. N. A. (2001). Habitat association in two genetic groups of the insect-pathogenic fungus Metarhizium anisopliae: uncovering cryptic species? Appl Environ Microbiol 67, 1335-1342.

Freimoser, F. M., Screen, S., Bagga, S., Hu, G. \& St Leger, R. J. (2003). Expressed sequence tag (EST) analysis of two subspecies of Metarhizium anisopliae reveals a plethora of secreted proteins with potential activity in insect hosts. Microbiology 149, 239-247.

Hale, M. G., Moore, L. D. \& Griffin, G. J. (1978). Root exudates and exudation. In Interactions between Non-Pathogenic Soil Microorganisms and Plants, p. 475. Edited by Y. R. Dommergues \& S. V. Krupa. Amsterdam: Elsevier Scientific Publishing Company.

Han, K. H., Kim, J. H., Moon, H., Kim, S., Lee, S. S., Han, D. M., Jahng, K. Y. \& Chae, K. S. (2008). The Aspergillus nidulans esdC (early sexual development) gene is necessary for sexual development and is controlled by veA and a heterotrimeric G protein. Fungal Genet Biol 45, 310-318.

Harman, G. E. (2006). Overview of mechanisms and uses of Trichoderma spp. Phytopathology 96, 190-194.

Harman, G. E. \& Shoresh, M. (2007). The mechanisms and applications of symbiotic opportunistic plant symbionts. In Novel Biotechnologies for Biocontrol Agent Enhancement and Management, p. 374. Edited by M. Vurro \& J. Gressel. Dordrecht, The Netherlands: Springer.

Hu, G. \& St. Leger, R. J. (2002). Field studies using a recombinant mycoinsecticide (Metarhizium anisopliae) reveal that it is rhizosphere competent. Appl Environ Microbiol 68, 6383-6387.

Kerry, B. R. (2000). Rhizosphere interactions and the exploitation of microbial agents for the biological control of plant-parasitic nematodes. Anпu Rev Phytopathol 38, 423-441.

Milner, R. J. (1992). Selection and characterization of strains of Metarhizium anisopliae for control of soil insects in Australia. In Biological Control of Locusts and Grasshoppers, pp. 200-207. Edited by C. J. Lomer \& C. Prior. Wallingford, UK: CAB International; International Institute of Tropical Agriculture.

O'Brien, T. R. (2008). Metarhizium anisopliae's persistence as a saprophyte, genetic basis of adaptation and role as a plant symbiont. $\mathrm{PhD}$ thesis, University of Maryland.

Pingel, R. L. \& Lewis, L. C. (1996). The fungus Beauveria bassiana (Balsamo) Vuillemin in a corn ecosystem: its effect on the insect predator Coleomegilla maculata De Geer. Biol Control 6, 137-141.

Prior, C. (1992). Discovery and characterization of fungal pathogens for locust and grasshopper control. In Biological Control of Locusts and Grasshoppers, pp. 159-180. Edited by C. J. Lomer \& C. Prior. Wallingford, UK: CAB International.

Quesada-Moraga, E., Navas-Cortés, J. A., Maranhao, E. A. A., Ortiz-Urquiza, A. \& Santiago-Álvarez, C. (2007). Factors affecting the occurrence and distribution of entomopathogenic fungi in natural and cultivated soils. Mycol Res 111, 947-966.

Rovira, A. D. (1965). Plant root exudates and their influence upon soil microorganisms. In Ecology of Soil-Borne Plant Pathogens, Prelude to Biological Control, pp. 571. Edited by K. F. Baker, W. C. Snyder, R. R. Baker \& others. Los Angeles: University of California Press. 
SAS Institute Inc (2006). SAS/Procedures guide version $S A S \circledR$ 9.1.3. Cary, NC, USA: SAS Institute, Inc.

St. Leger, R. J. (2007). Metarhizium anisopliae as a model for studying bioinsecticidal host pathogen interactions. In Novel Biotechnologies for Biocontrol Agent Enhancement and Management, pp. 179-204. Edited by M. Vurro \& J. Gressel. New York/Heidelberg: Springer.

St. Leger, R. J. (2008). Studies on adaptations of Metarhizium anisopliae to life in the soil. J Invertebr Pathol 98, 271-276.

Wagner, B. L. \& Lewis, L. C. (2000). Colonization of corn, Zea mays, by the entomopathogenic fungus Beauveria bassiana. Appl Environ Microbiol 66, 3468-3473.

Wang, C. S. \& St. Leger, R. J. (2007). The MAD1 adhesin of Metarhizium anisopliae links adhesion with blastospore production and virulence to insects, and the MAD2 adhesin enables attachment to plants. Eukaryot Cell 6, 808-816.

Wang, C. S., Hu, G. \& St. Leger, R. J. (2005). Differential gene expression by Metarhizium anisopliae growing in root exudate and host (Manduca sexta) cuticle or hemolymph reveals mechanisms of physiological adaptation. Fungal Genet Biol 42, 704-718.

Wang, S. B., Leclerque, A., Pava-Ripoll, M., Fang, W. G. \& St. Leger, R. J. (2009). Comparative genomics using microarrays reveals divergence and loss of virulence associated genes in host-specific strains of the insect pathogen Metarhizium anisopliae. Eukaryot Cell 8, 888-898.

Wolfger, H., Mamnun, Y. M. \& Kuchler, K. (2001). Fungal ABC proteins: pleiotropic drug resistance, stress response and cellular detoxification. Res Microbiol 152, 375-389.

Woo, S. L., Scala, F., Ruocco, M. \& Lorito, M. (2006). The molecular biology of the interactions between Trichoderma spp., phytopathogenic fungi, and plants. Phytopathology 96, 181-185.

Zimmermann, G. (2007). Review on safety of the entomopathogenic fungus Metarhizium anisopliae. Biocontrol Sci Technol 17, 879-920.

Edited by: W. Achouak 